\title{
Bending and Compressive Analysis of Epoxy Resins Modified with Low-polar Solvent Solution of Polysulphone
}

\author{
VASILE BRIA ${ }^{1}$, CRISTIAN MUNTENITA ${ }^{1 *}$, IULIA GRAUR ${ }^{1,2}$ \\ 'Dunarea de J os University of Galati, Research and Development Centre for Thermoset Matrix Composites, 47 Domneasca Str., \\ 800008, Galati, Romania \\ Diagnose and Measurement Group, 41 Rosiori, 800055, Galati, Romania
}

\begin{abstract}
The memory shape materials seem to be extremely promising materials for medical applications especially as inserts to support the muscular system. In the case of memory shape polymers a supplementary issue is related to their bio-compatibility such as they can be rejected by the organism even their properties are fitting the requirements. Present study started from the hypothesis that mixing the epoxy resin with other polymers some valuable materials could be obtained especially for energy storage. The epoxy resins possess extraordinary properties (relatively to other thermoset polymers) but they also show an excellent stability that generates problems when this type of materials should be neutralized. Epoxy resins also show low water or other liquids absorption due to their low porosity and they cannot be used for energy storage applications when mobility of charge carriers is ensured by liquid phase. A polymer with high porosity used for membrane formation is the polysulfone and, in this regard, tests were performed to analyse the ways to mix an epoxy resin with polysulfone. The idea had generated a study regarding the properties of such a mixture together with the condition that had to be reached to successfully get the mixture. Low-polar solvent solution of polysulfone had been obtained with 1-methyl-2-pyrrolidinone. After compatibility tests, 15 and $20 \%$ of this solution was added to the components of the epoxy systems -with the epoxy resin -and formed materials were analysed by mechanical means-compressive and three-point bending - the surprise was that some materials had showed memory shape properties.
\end{abstract}

Key words: three-point bending test, compressive test, polysulfone, 1-methyl-2pyrrolidinone, epoxy resins

Memory shape materials used in medical devices need to be evaluated for material characteristics including the mechanical properties. Polysulfone is an engineering polymer with high thermal, oxidative and hydrolytic stability. It is a transparent, amorphous polymer with high strength resistance [1, 2]. However, as new applications continue to emerge, the properties of the polysulfone need to be modified appropriately. One approach to achieving that goal is through blending with other polymers, both thermoplastics and thermosets [3]. During the past decade, smart materials and structures or intelligent material systems have received increasing attention because of their great scientific and technological significance $[4,5]$. Shape-memory materials are one of the major elements of intelligent/smart composites because of their unusual properties, such as the shapememory effect, or large recoverable stroke (strain), high damping capacity and adaptive properties which are due to the (reversible) phase transitions in the materials [6]. Shape-memory polymers possess the ability to memorize a permanent shape that can substantially differ from their initial temporary shape [7]. However, their recovery can be triggered by various external stimuli, such as heat [8], light [9], electricity [10], magnetic field or solution [11]. The shape memory effect is caused by the transition of a crosslinking polymer from a state dominated by entropic energy (rubbery state) to a state dominated by internal energy (glassy state) as the temperature decreases [12] and is maintained by covalent netpoints (for polymer networks), or by the phase of high thermal transition (for thermoplastic elastomers) [13]. It will not be an exaggeration to say that the appearance of the shapememory effect in polymers is one of the revolutionary steps in the field of active materials research [14]. A variety of shape memory polymers have been invented and welldocumented in the literature, while presently new ones keep on emerging every week, if not every day [15-17]. Traditionally, a shape recovery thermo-mechanical cycle consists of on a set of steps as illustrated in figure 1 . These materials have several advantages: high elastic deformation (strain up to more than $200 \%$ for most of the materials), low cost, low density, and potential biocompatibility and bio-degradability. They also have a broad range of application temperatures that can be tailored, tunable stiffness, and are easily processed [18]. Like in other fields of applications, they have been proved to be suitable substitutes to metallic ones because of their flexibility, bio-compatibility and wide scope of modifications [19, 20]. Owing to their superior mechanical properties, ease of processing, and excellent chemical resistance, epoxy based polymers have been widely used as structure, coating, and adhesive materials in many demanding applications [21]. The use of epoxy polymers as functional materials, however, remains rather rare. Specifically for the shape memory effect of epoxy polymers, only sporadic examples have been mentioned in the literature [22-25].

We report a novel type of polymer blends very simple to fabricate for good shape memory properties. This blend consists of mixing several components in different concentrations: solution of polysulfone in 1-methyl2pyrrolidinone and this solution into epoxy systems, in order to overcome the mechanical weakness of the materials. The objective of this study is to gather valuable scientific results regarding tested materials through the mechanical properties-compressive and three-pointbending.

\footnotetext{
* email: cristian.muntenita@ugal.ro
} 


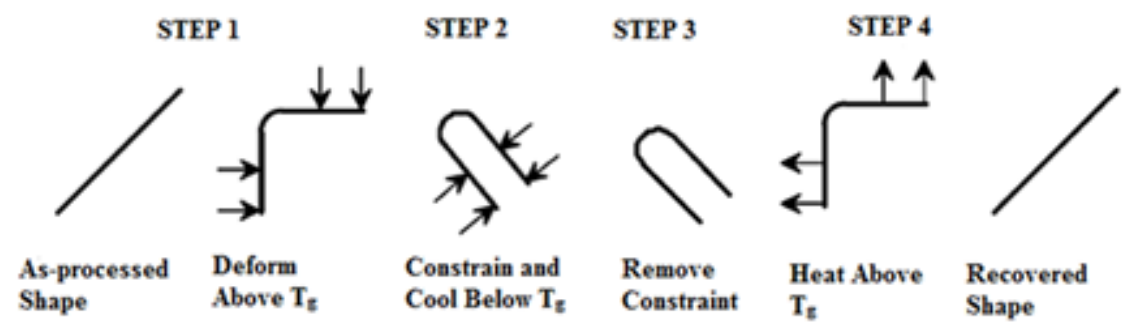

Fig.1.Schematic of the idealized thermomechanical cycle leading to unconstrained strain recovery for a shape memory polymer

[8]

\section{Experimental part}

Getting improved properties of polymeric composites involve several stages: establishing the polymer matrix and the additive type, choosing the formation process and also the type of tests to which materials will be subjected of. Polysulfone in 1-methyl-2pyrrolidinone had been mixed with the components of the epoxy systems - after compatibility tests of 1-methyl-2pyrrolidinone with the epoxy resin. Low-polar solvent solution of polysulfone had been obtained as follows: $25 \%$ polysulfone and $75 \% 1-$ methyl-2pyrrolidinone. After compatibility tests, 15 and $20 \%$ of this solution was added to the components of the epoxy systems.

Two epoxy systems were chosen mostly because of their different bisphenol A content, namely Epoxy Resin C (R\&G Gmbh Waldenbuch) and Epoxy Resin HT2 (R\&G Gmbh Waldenbuch). These two polymers have different gel time and different brittleness. Blending tests of polysulfone solutions with other epoxy resins were developed also for EPIPHEN RE402-DE4020 epoxy system but, in this case the results were not promising due to flexibility of epoxy resin and its gel time. Bending and compression tests were applied to samples. The
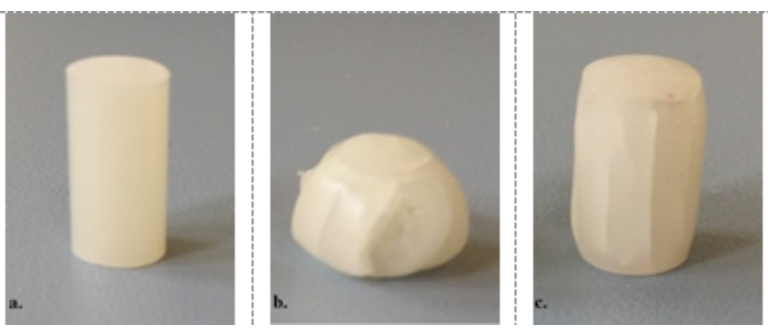

Fig. 2. Compressive specimens images: a. before compressive testing; b. immediately after compressive test; c. after 30 MINof compressive testing.
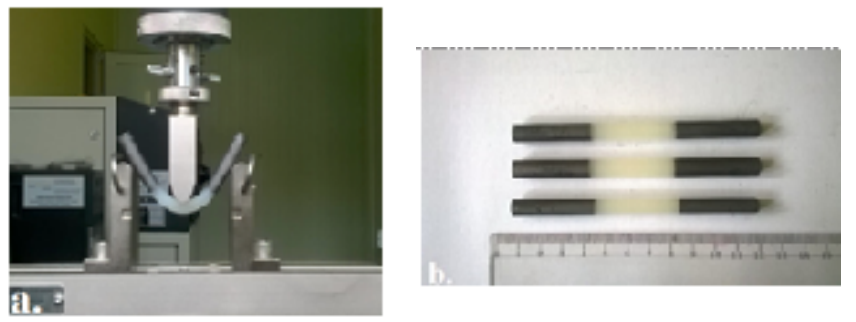

a.?
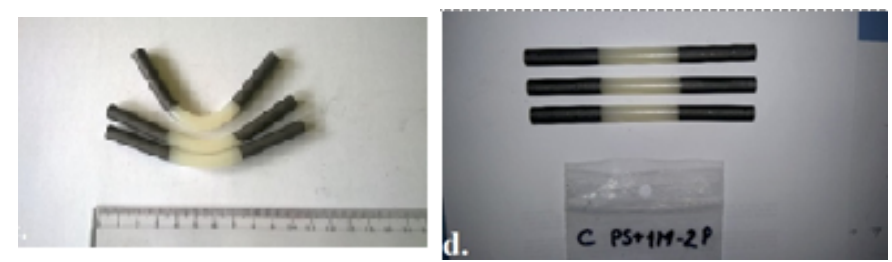

Fig.3. Three-point bending test images. a-specimen during three-point bending test,

b - specimens before testing, c -specimens immediately after testing, $d$ - specimens a few hours after three-poin bending tests experimental equipment used in this study was an Instron 8850 Testing Instrument. Measurements on this equipment viewed compressive and bending mechanical properties of materials. The applied load was $2 \mathrm{kN}$ for bending and $25 \mathrm{kN}$ for compression test. Compressive testing is a very common testing method that is used to establish the compressive force or crush resistance of a material and the ability of the material to recover after a specified compressive force is applied and even held over a defined period of time (fig.2).

\section{Results and discussions}

For polymer blends obtained between the two epoxy resins and polysulfone solution breaking forces could not be considered authentic because these materials have a very special behavior, therefore they do not break during the three-points bending tests. So it may be said that these materials are extremely flexible ones. Besides the fact that these materials do not break during bending tests, they have a distinctive feature, namely shortly after bending tests they return to original form. In figure 3 it can be seen that after just 10 min the material recovers $90 \%$, and after a few hours specimens possess traditional form.

Figure 4 shows Elasticity limitmeasured by compression for $\mathrm{C}$ and $\mathrm{HT} 2$ epoxy resins. Elasticity limit is the maximum stress or force per unit area within material that can arise before the onset of permanent deformation. So, for $15 \%$ polysulfone solution in 1-methyl-2pyrrolidinone for both $\mathrm{C}$ and HT2 materials, the elasticity limit marks the end of elastic behavior and the beginning of plastic behavior for

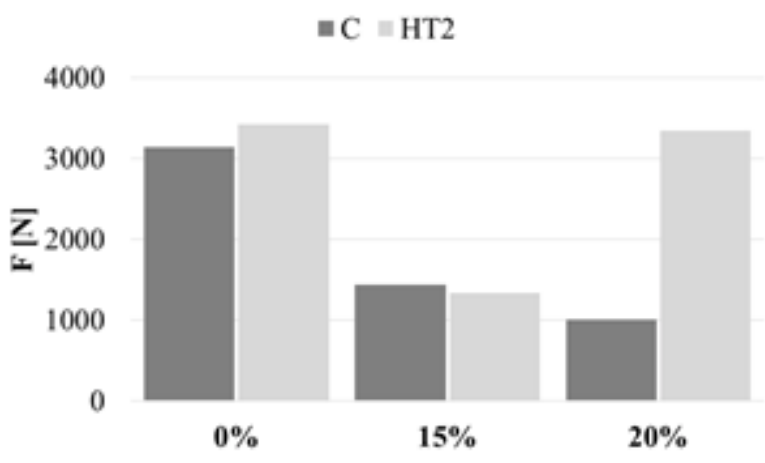

Concentrations of polysulfone in 1-methyl-2pyrrolidinone Fig.4. Elasticity limit-Compressive

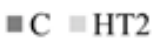

3000

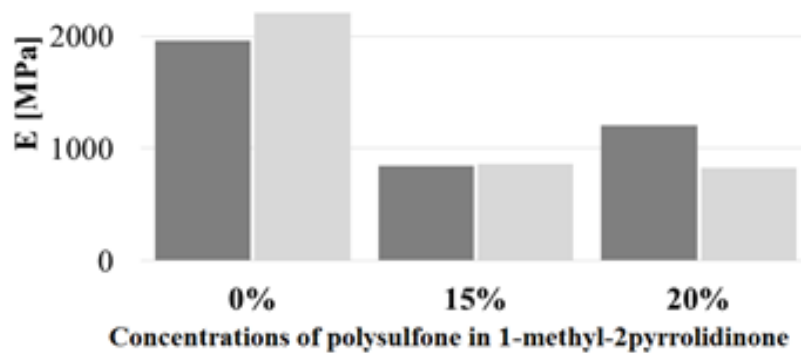

Fig.5. Elastic Modulus-Compressive 
$-\mathrm{C} 0-\mathrm{C} 15-\mathrm{C} 20$

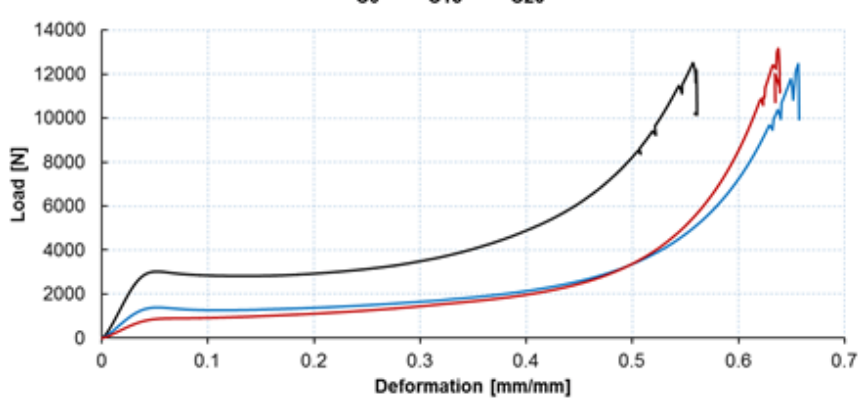

Fig.6. Compressive load-deformation diagram for C epoxy system

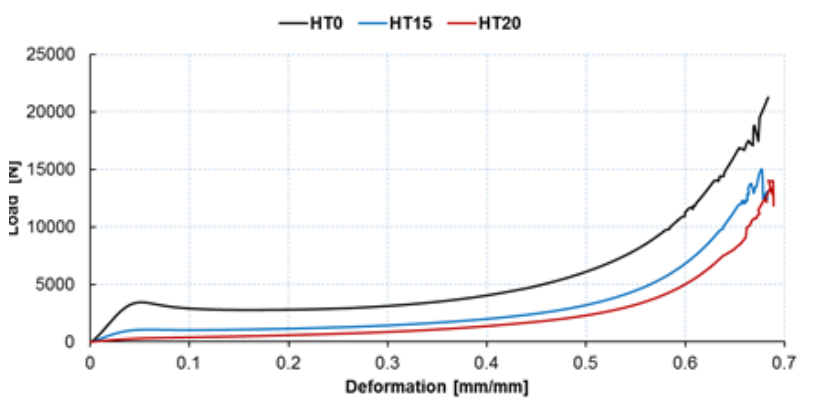

Fig.7. Compressive load-deformation diagram for HT2 epoxy system

$\approx \mathrm{C}=\mathrm{HT} 2$

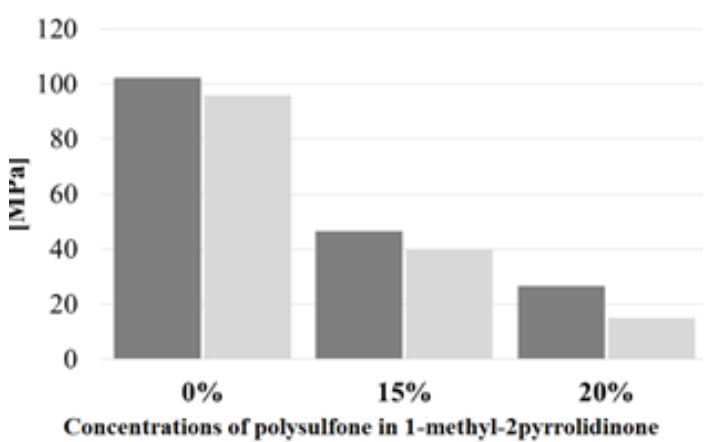

Fig.8. Elasticity limit- Bending

only $1500 \mathrm{~N}$. It is obviously that maximum elasticity limit at compressive is achieved for HT2 epoxy resin. The compression elastic modulus of the formed materials is illustrated in figure 5 . It might be concluded that the higher value is reached also for HT2 epoxy resin. The samples return to their original shape after the load is removed.

With the increase of solution of polysulfone concentration the elasticity limit measured during three point bending tests of the materials correspondingly decreased (fig.8). Analyzing the bending elastic modulus (fig.9) itmight be noticed that the polysulfone solution ratio has a considerable importance, because with increasing its ratio, the bending elastic modulus decreases. As it can be observed fromFIGURE 10 and figure 11, for bending tests, the epoxy resins modified with low-polar solvent solution of polysulfone have a rubber-like behavior. The load rises to the maximum point with a sigmoidal relationship to the deformation. The rupture does not occur.

\section{Conclusions}

Besides the fact that these materials did notbreak during three-point bending tests, they have a particular characteristic, namely that when the stress is removed the material returns to the dimension it had before the load was applied. Moreover, materials formed with $\mathrm{C}$ and $\mathrm{HT} 2$ resins, after bending tests does not show evidence of local plastic deformation or any sign of damage. The shape recovery after bending, shown in figure 3 is the most

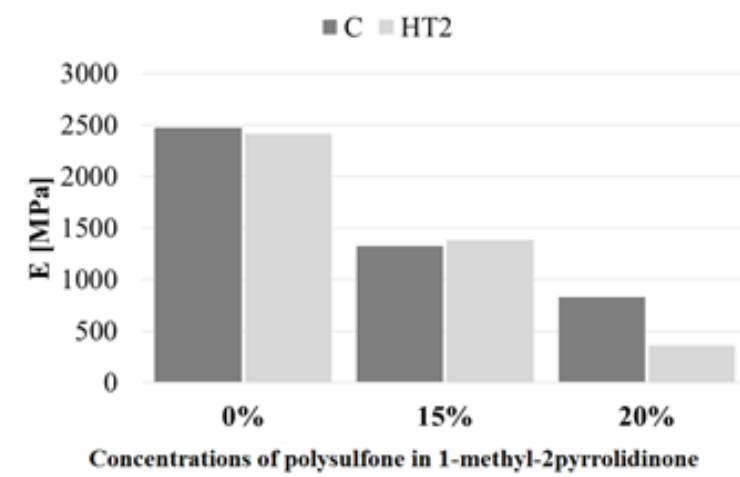

Fig.9. Elastic modulus- Bending

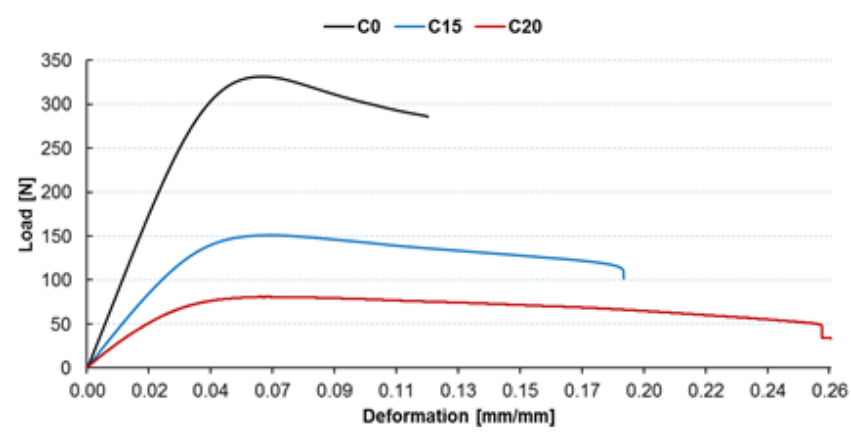

Fig. 10. Bending load-deformation diagram for C epoxy system

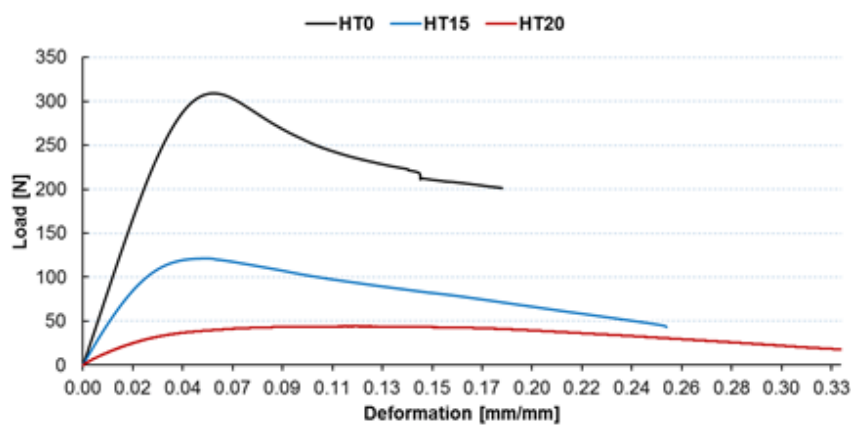

Fig.11. Bending load-deformation diagram for HT2 epoxy system

probably related to entropy-elasticity of polysulfone in 1methyl-2pyrrolidinone solution. In the case of compression tests, for both types of materials ( $\mathrm{C}$ based or HT2 based) some cracks are developed along the loading direction but, as in the case of bending tests, after a while the samples are recovering their initial shape. More studies related to these two materials have to be designed and developed such as to characterize their memory shape features, and an important one is to identify the external factors that may influence the shape recovery.

Acknowledgements: The authors would like to acknowledge the financial contribution of the Project 12 P01 02421 (C11) /31.08.2012 (code SMIS 50414).

\section{References}

1. DEMEUSE, M. T., High Temperature Polymer Blends, Woodhead Publishing Limited, 2014, p. 170.

2. PINTILIE, S. C., TIRON, L.G., BIRSAN, I.G., GANEA, D., BALTA, S., Mat. Plast., 54, no.2, 2017, p. 258.

3. SASTRI, V. R., Plastics in medical devices: properties, requirements, and applications. William Andrew, 2013, p.

4. LI, X., SERPE, M. J., Adv. Funct. Mater., 26, no.19, 2016, p. 3286. 5. WILBUR, C. S., ILHAN, A. A., DRYVER, R. H., Smart Structures and Materials 1997: Smart Materials Technologies, 3040, San Diego, California, 1997, p. 236. 
6. WEI, Z. G., SANDSTROM, R., MIYAZAKI, S., J. Mater. Sci. , 33, nr. 15, 1998, p. 3743.

7. LENDLEIN, A., LANGER, R., Sci. , 296, no. 5573, 2002, p. 1675.

8. GALL, K., DUNN, M. L., LIU, Y., FINCH, D., LAKE, M., MUNSHI, N. A., Acta Mater., 50, nr. 20, 2002, p. 5115.

9. LENDLEIN, A, JIANG, H., JUNGER, O., LANGER, R., Nature, 434, 2005, p. 879.

10. PAIK, I. H., GOO, N. S., JUNG, Y. C., CHO, J. W., Smart Mater. Struct., 15, nr. 5, 2006, p. 1476.

11. LV, H. B., LENG, J. S., LIU, Y. J., DU, S.Y., Adv. Eng. Mater. 10, nr. 6 , 2008, p. 592.

12. QI, H. J., NGUYEN, T. D., CASTRO, F., YAKACKI, C. M., SHANDAS, R., J. Mech. Phis. Solids., 56, nr. 5, 2008, p.1730.

13. CHEN, Y.-C., LAGOUDAS, D. C., J. Mech. Phis. Solids., 56, nr. 5, 2008, p. 1752.

14. LENG, J., DU, S., Shape-Memory Polymers and Multifunctional Composites, CRC Press, Boca Raton, 2010, p. 204.

15. HUANG, W. M., DING, Z., WANG, C. C., WEI, J., ZHAO, Y., PURNAWALI, H., Mater. Today, 13, no. 7-8, 2010, p. 54.
16. MATHER, P. T., LUO, X., ROUSSEAU, I. A., Annu. Rev. Mater. Sci., 39, 2009, p. 445.

17. ROUSSEAU, I. A., Polym. Eng. Sci., 48, no.11, 2008, p. 2076. 18. LIU, C., QIN, H., MATHER, P.T., J. Mater. Chem., 17, no. 16, 2007, p. 1543.

19. RATNA, D., KARGER-KOCSIS, J., J. Mater. Sci., 43, no. 1, 2008, p. 254.

20. XIE, T., ROUSSEAU, I. A., Polym. , 50, no. 8, 2009, p. 1852.

21. BOLCU, D., SAVA, M., DINITA, A., MIRITOIU, C. M., BACIU, F., Mat. Plast. 53, no.1, 2016, p.26.

22. BEHL, M., LENDLEIN, A., Matter. Today, 10, 2007, p. 25.

23. MERLINE, J. D., REGHUNADHAN NAIR, C.P., NINAN, K.N., J. Macromol. Sci. Part. A, 45, 2008, p. 312.

24. PATRICK, M. T., LUO, X., ROUSSEAU, I. A., Annu. Rev. Mater. Res., 39, 2009, p. 450.

25. LIU, C., QIN, H., MATHER, P.T., J. Mater. Chem., 17, no.16, 2007, p.1553.

Manuscript received: 18.06 .2018 